\title{
A construção de um modelo ideal de monarca no livro de linhagens do Conde Pedro de Barcelos
}

Adriana Mocelim de Souza Lima

\section{(2) OpenEdition}

\section{Journals}

\section{Edição electrónica}

URL: http://journals.openedition.org/medievalista/662

DOI: 10.4000/medievalista.662

ISSN: 1646-740X

\section{Editora}

Instituto de Estudos Medievais - FCSH-UNL

Refêrencia eletrónica

Adriana Mocelim de Souza Lima, «A construção de um modelo ideal de monarca no livro de linhagens do Conde Pedro de Barcelos », Medievalista [Online], 9 | 2011, posto online no dia 02 janeiro 2011, consultado no dia 01 maio 2019. URL : http://journals.openedition.org/medievalista/662 ; DOI : 10.4000/medievalista.662

(C) IEM 
Titulo: A construção de um modelo ideal de monarca no livro de linhagens do Conde Pedro de Barcelos

Autor(es): Adriana Mocelim de Souza Lima

Enquadramento Institucional: Universidade Federal do Paraná - Brasil; membro do Núcleo de Estudos Mediterrânicos da UFPR

Contacto: drikamocelim@yahoo.com.br

Fonte: Medievalista [Em linha]. №9, (Dezembro 2010). Direc. José Mattoso. Lisboa: IEM. Disponível em: http://www2.fcsh.unl.pt/iem/medievalista/

ISSN: 1646-740X

\section{Resumo}

A partir do Livro de Linhagens, escrito pelo Conde Pedro Afonso, foi elaborado o presente artigo, buscando elementos que pudessem contribuir para a elaboração de uma imagem de Rei ideal. Ao longo do Livro de Linhagens o Conde pode acentuar a ancestralidade da monarquia, demonstrando assim a necessidade da mesma enquanto reguladora da sociedade e principal responsável pela aplicação da Justiça, em todo o Reino, além de seu papel na promoção do bem comum, baseado no bom relacionamento entre rei e nobreza. O bom rei é apresentado ainda como o rei cristão, temente a Deus. É o rei da Reconquista, que luta em defesa da cristandade, combate mouros, reconquista territórios e garante a unidade da cristandade. Essa imagem "ideal de Rei" contrasta com uma realidade bem diferente, marcada por revoltas nobiliárquicas, disputas entre reis e infantes. Reis que na busca da centralização não souberam relacionar-se com a nobreza, não levaram em conta seus valores e tradições, não proveram a paz e nem garantiram o bem comum em seus reinos.

\section{Palavras-chave:}




\section{Abstract}

A partir do Livro de Linhagens, escrito pelo Conde Pedro Afonso, foi elaborado o presente artigo, buscando elementos que pudessem contribuir para a elaboração de uma imagem de Rei ideal. Ao longo do Livro de Linhagens o Conde pode acentuar a ancestralidade da monarquia, demonstrando assim a necessidade da mesma enquanto reguladora da sociedade e principal responsável pela aplicação da Justiça, em todo o Reino, além de seu papel na promoção do bem comum, baseado no bom relacionamento entre rei e nobreza. O bom rei é apresentado ainda como o rei cristão, temente a Deus. É o rei da Reconquista, que luta em defesa da cristandade, combate mouros, reconquista territórios e garante a unidade da cristandade. Essa imagem "ideal de Rei" contrasta com uma realidade bem diferente, marcada por revoltas nobiliárquicas, disputas entre reis e infantes. Reis que na busca da centralização não souberam relacionar-se com a nobreza, não levaram em conta seus valores e tradições, não proveram a paz e nem garantiram o bem comum em seus reinos.

Keywords:

\section{A construção de um modelo ideal de monarca no livro de linhagens do Conde Pedro de Barcelos}

\section{Adriana Mocelim de Souza Lima}

Comunicação apresentada a 13 de agosto de 2009, no VIII Encontro Internacional de Estudos Medievais organizado pela Associação Brasileira de Estudos Medievais.

O Livro de Linhagens escrito pelo Conde Pedro Afonso apresenta exemplos de tradições familiares, destaca a importância da linhagem, do sangue, na constituição da nobreza, fornece uma galeria de tipos exemplares, modelos de virtude. A obra constituise como uma forma de transmissão ideológica, que ao mesmo tempo reforça a legitimidade de sangue da nobreza, que cerca o rei, e fornece a ela um modelo de 
estruturação interna, a partir da caracterização do bom e do mau rei, além da caracterização do nobre ideal.

Ao longo do Livro de Linhagens são encontradas referências ao código ético da Cavalaria medieval, na definição dos personagens e na recriação do ambiente em que se movimentam, apresentando assim um modelo de agir. Ocorre uma identificação entre nobreza e Cavalaria, expressando um modelo ideal de vida para a aristocracia do século XIV.

O Conde fornece à nobreza, através do modelo cavaleiresco "unha conciencia de identidade, unha conciencia da existencia como grupo ou clase social ben definida dentro do conxunto da sociedade."1 Constrói esse ideal a partir de valores ligados ao sangue, ao patrimônio, à tradição e à honra, valores que trariam coesão e estruturação à nobreza, que vivia um momento de desestruturação e perda de sua justificativa de defensora do reino, após o término das operações de Reconquista, no século XIV.

Os valores apresentados pelo Conde ao caracterizar o bom e o mau rei e o nobre são praticamente os mesmos. A monarquia não é tratada na obra como algo exterior e diferencial do nobiliário. As relações de parentesco a unem com a nobreza, "os modelos culturais son compartidos porque son os mesmos; aínda máis, a monarquía tem a súa orixe na nobreza, existe por ela e em virtude dela." ${ }^{2}$ A nobreza constitui-se como a linhagem da monarquia.

O rei é visto, durante o século XIV, na Europa Medieval, como sendo o regulador das pressões e relações internas da nobreza, que se dão ainda numa esfera baseada em relações pessoais. Nesse contexto, a primazia régia é construída por meio da promoção do bem comum no Reino, fundamentado no equilíbrio entre concessões e cobranças. $\mathrm{O}$ rei teria o direito de "impor a todos a sua vontade, porque ela é conforme e evidentemente à vontade geral, ao bem comum."3

O século XIV é marcado pela existência de relações e alianças políticas que extrapolam fronteiras físicas. Laços de fidelidade e honra uniam nobres a seus senhores, de maneira que

\footnotetext{
${ }^{1}$ PAREDES MIRÁS, Maria del Pilar. Mentalidade nobiliária e nobreza galega, ideal e realidade na Baixa Idade Media. Galiza: Toxosoutos, 2002, p. 80.

${ }^{2}$ Ibidem, p. 80.

${ }^{3}$ FOURQUIN, Guy. Senhorio e Feudalidade na Idade Média. Lisboa: Edições 70, 1987, p. 105
} 
nenhum dos critérios pelos quais se pode atribuir superioridade social a uma linhagem tem que ver com a sua 'nacionalidade,' mas antes com aqueles vínculos que as ligavam aos reis que iniciaram a Reconquista, como o Rei Rodrigo, ao grande antepassado da melhor nobreza peninsular, Cid o Campeador, ou aos outros heróis da gesta anti-islâmica. ${ }^{4}$

A fidelidade ao juramento vassálico era mais forte do que a fidelidade em relação ao território de nascimento. Sendo a ligação dos nobres com o ideal da Reconquista bastante acentuada, a ponto de estruturar as relações dessa nobreza, constituindo-se no seu grande modelo.

Ao apresentar um perfil do bom rei o Conde fornece um modelo aos nobres, constrói dessa maneira uma identidade do que significava ser nobre aos membros da nobreza de Corte, construída a partir do modelo régio.

Esse modelo de rei e de nobre foi sintetizado pelo Conde a partir de narrativas que "circulavam oralmente (nos meios palacianos, aristocráticos, nos saraus das Cortes, nas cantigas trovadorescas) e tinham uma relativa independência de suas versões escritas". 5 Essas narrativas passaram a circular por entre a nobreza após a estabilização política promovida no reinado de Dinis, momento em que a mentalidade cavaleiresca sofreu uma valorização, através da difusão de "um culto generalizado da poesia trovadoresca e dos romances de cavalaria."6.

Dentre os vários tipos de narrativas que se encontram intercalados aos trechos genealógicos do Livro de Linhagens, o perfil do bom rei e do nobre é buscado nos trechos anedóticos e nos trechos históricos. Os trechos anedóticos trazem referências acerca da honra de determinadas famílias, além de modelos de como se deve cumprir o código vassálico, além de relatos de traições. Já os trechos históricos trazem biografias de determinadas personagens e exemplos de vassalidade.

\footnotetext{
${ }^{4}$ MATTOSO, José. A nobreza medieval portuguesa no contexto peninsular. Actas das IV Jornadas LusoEspanholas de História Medieval. Porto: Universidade do Porto/Instituto de Documentação Histórica da Faculdade de Letras da Universidade do Porto, 1999, 1040.

${ }^{5}$ COSTA, Ricardo Luiz Silveira da. A mentalidade de cruzada em Portugal (sécs XII-XIV). Disponível em: www.ricardodacosta.com. [Consultado 31.03.2010], p. 11.

${ }^{6}$ Ibidem, p. 11.
} 
Ao buscar as origens da instituição monárquica em Adão "falaremos primeiro do linhagem do homees e dos reis de Jerusalem des Adam ataa nacença de Jesu Christo,"7 o Conde visava apresentar a ancestralidade da instituição, além de reforçar o fato de que a sociedade necessitava da monarquia. $\mathrm{O}$ recurso à história para poder apresentar a linhagem dos reis de Portugal não só

contribuye a sacar la figura del príncipe de los tiempos primordiales y a inscribirla em uma perspectiva histórica, sino que, al relacionarla con un reino concreto y con sus habitantes, irá aportando elementos para la construcción de otros conceptos, como los de estado y nación. ${ }^{8}$

O Livro de Linhagens pode ser analisado como um espelho de reis e de nobres, obra onde as virtudes do bom rei e do nobre, assim como os vícios que podem e devem ser evitados podem ser contemplados. A partir do modelo de bom rei apresentado pelo Conde, obtém-se o modelo do bom nobre, que segue as características atribuídas ao monarca.

Nos primeiros sete títulos do Livro de Linhagens, e em determinados trechos do restante da obra, onde o Conde apresenta as linhagens nobiliárquicas, destacando-se o título XXI, “D'El rei Ramiro, donde decendeo a geeraçom dos boos e nobres fidalgos de Castela e Portugal, e d'algũus feitos que ele de os que dele descenderam feezeram,"9 o Conde Pedro Afonso enumera as características e virtudes que um monarca deve possuir. O Conde ao narrar tais virtudes projeta a imagem de um Rei ideal.

A imagem de Bom Rei apresentada pelo Conde pode ser analisada a partir de dois aspectos, uma imagem moralizante, ressaltando determinadas virtudes, e uma imagem funcional, destacando a função a ser desempenhada pelo rei dentro do reino. Já a imagem do mau Rei é apresentada a partir da não valorização do cristianismo e da negação de determinadas virtudes.

O Rei Cristão. A imagem do Rei Cristão é construída a partir de uma concepção Cristã da História. Para chegar aos reis de Portugal faz uso de uma cronologia com enfoque

\footnotetext{
${ }^{7}$ PEDRO, Conde D. Livro de Linhagens. [1340] In: Portugaliae Monumenta Histórica, Nova Série. Ed. crítica por José Mattoso. Lisboa: Academia das Ciências, 1980. Volume I, p. 57.

8 PALACIOS MARTÍN, Bonifacio. El mundo de las ideas políticas en los tratados doctrinales españoles: los espejos de príncipes (1250-1350). In: Anais da XXI Semana de Estudios Medievales. Pamplona: Departamento de Educación y Cultura de Navarra, 1995, p. 483.

${ }^{9}$ PEDRO, Conde D. Livro de Linhagens... Op. Cit., p. 204.
} 
bíblico, onde Adão é apresentado como a base do tronco, do qual descendem todos os homens. O Conde emprega na descrição um caráter universalista, frente aos particularismos que marcam a Península Ibérica de 1340. Amarra a atuação do rei a referências histórico-simbólicas, valorizadas do passado bíblico, clássico e hispanogodo, característica essa específica da Península Ibérica.

O rei cristão é apresentado inicialmente como o rei temente a Deus, baseado em exemplos de personagens bíblicos, como pode-se observar na apresentação do rei Davi: "foi homem que temeo Deus, e foi mui bõo rei e bõo profeta, e fez os Salmos e a Lei." Em seguida vem a conversão ao cristianismo e sua função como defensor da fé e de seu povo. O rei cristão é o rei da Reconquista, como pode ser percebido na descrição do rei Ramiro das Astúrias "este houve muitas batalhas com Mouros e conquereo grandes terras. E deste Rei Ramiro o segundo saio a boa geeraçom dos fidalgos da Espanha." "1 Essa ligação do Rei com a Reconquista ao mesmo tempo justifica-o perante a sociedade e o caracteriza como o responsável por zelar pela unidade da Cristandade.

O Rei Virtuoso. O rei virtuoso é aquele que se mostra esforçado em suas conquistas territoriais e na defesa da cristandade, honra os seus e governa com mansidão e cortesia. A virtude mais citada ao longo do texto é a lealdade, símbolo do compromisso que deve reger as relações vassálicas, como exemplo observa-se a descrição do rei Artur: "foi boo rei e leal, e conquereo todolos seus emmigos, e passou por muitas aventuiras, e fez muitas bondades, que todolos tempos do mundo falarom delo." ${ }^{12} \mathrm{O}$ rei exige fidelidade e se torna digno dela ao cultivar as virtudes que devem caracterizá-lo. Os exemplos de lealdade, empregados pelo Conde, vêm de lugares distantes como a Bretanha, lugar idealizado, onde a lealdade era prática comum, e a deslealdade era substituída pela afirmação do juramento de vassalagem.

O Rei Juiz. Ao valorizar a imagem do rei justo, o Conde ressalta que o exercício da justiça dentro do reino é uma forma de recuperar e manter a ordem. Nada mais pertinente de se escrever quando se está inserido numa realidade marcada por antagonismos e disputas entre rei e nobreza. É dever do rei zelar pelo exercício da justiça, valorizando costumes e tradições, dessa forma a ordem retornaria ao reino,

\footnotetext{
${ }^{10}$ Ibidem, p.63.

${ }^{11}$ Ibidem, p. 106.

${ }^{12}$ Ibidem, p. 89-90.
} 
como exemplo encontra-se Afonso III de Portugal: "El rei dom Afonso foi mui boo rei e justiçoso, e manteve sempre seu reino em paz e sem contenda nem ũa."13 O Conde Pedro Afonso ao longo do Livro de Linhagens formula regras de conduta aos príncipes e a todos os que se ocupam de política dentro do reino.

O Rei conquistador. Ao apresentar o rei conquistador como o Rei da Reconquista, o Conde pode estar estimulando o papel cruzadístico do rei e consequentemente da nobreza, dentro do panorama da Península Ibérica, às vésperas da Batalha do Salado, 1340. Ao reavivar o ideal da Reconquista peninsular na luta contra o infiel, ideal esse gerador da unidade em torno de um ideal comum, o Conde ao mesmo tempo fortalece o rei e realça o papel da nobreza, justificando sua função social.

O Mau Rei. A imagem do Mau Rei é pautada numa Imagem Amoral (não cristã e não virtuosa): rei folom, ${ }^{14}$ cruel, herético, desleal, não sabe guardar seus amigos, não segue a fé de Cristo, além de ser adorador de ídolos e possuir maus conselheiros. Como exemplos cito o rei Porex da Bretanha: "foi mao rei, folom, e foi boo bevedor de vinho," 15 e o rei "Julianus Apostata, e foi mao e desleal, e partio-se da fe de Christus."16 Tais valores e virtudes associam-se, diretamente, à sociedade medieval portuguesa e à nobreza, formadas no interior de uma sociedade organizada para a guerra. Guerra que se constituiu enquanto "fator dominante que estrutura a sociedade e sua economia na Península Ibérica medieval." 17

Muitos desses valores são equiparados aos modelos transmitidos pelos romances de Cavalaria, difundidos de forma escrita no século XIV. Antes disso, transmitiam-se por via oral ou na forma de estratos, fornecendo alimento literário aos cavaleiros através da difusão das epopéias: "a realidade histórica misturava-se intimamente com a ficção literária e esta, por sua vez, inspirava e motivava a própria realidade." 18

\footnotetext{
${ }^{13}$ Ibidem, p. 129.

14 "Este vocablo pertenecía al estilo arcaico de los libros de caballería, [...], es evidente que follón en el estilo caballeresco era lo mismo que traidor o malandrín; [...], follonía es análogamente carácter traicionero; estes vocablos no sólo son sumamente comunes en la Edad Media desde los más antiguos monumentos, sino que hoy siguen siendo usuales con el mismo significado" COROMINAS, Joan. Diccinario Crítico Etimológico de la Lengua Castellana. Vol. II. Madrid: Editorial Gredos, 1954, p. 549550.

${ }^{15}$ PEDRO, Conde D. Livro de Linhagens... Op. Cit., p. 82.

${ }^{16}$ Ibidem, p.101.

${ }^{17}$ RUCQUOI, Adeline. História Medieval da Península Ibérica. Lisboa, Estampa, 1995, p. 217.

${ }^{18}$ MATTOSO, José. A nobreza medieval portuguesa: a família e o poder. Lisboa: Estampa, 1987, p. 357.
}

Medievalista online $\mathrm{N}^{0} 9$ | Janeiro - Junho 2011 ๑ IEM - Instituto de Estudos Medievais 7 
Um exemplo do perfil do "bom rei", apresentado pelo Conde, pode ser encontrado no relato do que teria dito o Conde Henrique, a seu filho Afonso Henriques, primeiro rei de Portugal

Filho, toda esta terra que te eu leixo dês Astorga ataa Coimbra, nom percas ende ũu palmo, ca eu a gaanhei com gram coita. E, filho, toma do meu coraçom algũa cousa, que sejas esforçado e sejas companheiro aos filhos d'algo, e da-lhe sas soldadas todas. E aos concelhos, faze-lhes honra, em guisa como hajam todos dereito, assi os grandes come os pequenos. E faze sempre justiça e aguarda em ela piadade aguisada, ca se um dia leixares de fazer justiça ũu palmo, logo outro dia se arredará de ti ũa braça, e do teu coraçom. E porem, meu filho, tem sempre justiça em teu coraçom e haverás Deus e as gentes. E nom consentas em nem ũa guisa que teus homees sejam soberbosos nem atrevidos em mal, nem façam pesar a nem ũu, nem digam torto, ca tu perderias porem o teu boo preço se o nom vedasses. ${ }^{19}$

Nesse trecho percebe-se que o "Bom Rei" deveria ser o conquistador de terras, esforçado e companheiro dos fidalgos. Deveria o rei honrar os Concelhos, as Vilas, garantindo os direitos de todos. Garantir o exercício da justiça era uma forma de alcançar proteção Divina e apoio das gentes do Reino. O Rei dentro da sociedade seria o ordenador, o árbitro das relações vassálicas, zelando para que seus homens não fossem soberbos e nem atrevidos.

A imagem de monarca ideal construída pelo Conde é definida pela figura de um rei que domina a hierarquia da nobreza, é Ele quem define escalões, confere prestígio. O rei constitui-se, nessa visão, como elemento chave na aplicação da Justiça e das leis. As leis elaboradas pelo rei são feitas para todos do reino. Dessa forma centralizaria sua autoridade, sobrepondo-a aos poderes locais. Essa centralização, no entanto só seria alcançada se governasse de maneira piedosa, com justiça e misericórdia. A Justiça deixaria de ser um privilégio para tornar-se um direito de todos, em nome do rei.

O Bom rei deveria desenvolver ações a fim de que houvesse, segundo coloca o Conde Pedro de Barcelos ainda no Prólogo do Livro de Linhagens, "amor" e "amizade" entre seus súditos, zelando e promovendo o bem comum. A figura do rei como regulador e

\footnotetext{
${ }^{19}$ PEDRO, Conde D. Livro de Linhagens... Op. Cit., p. 123-124.
} 
promotor do bem comum é necessária na medida em que a nobreza encontra-se fragmentada, desorientada e sem consciência de grupo e da importância que possui dentro do reino. Dois valores que permitiriam à nobreza ajudar-se mutuamente: "amor" e "amizade" estariam sendo deixados de lado.

A amizade, considerada como o maior de todos os bens, seria capaz de impedir discórdias. Valores como fidelidade, lealdade e assistência mútua estão ligados a ela. São valores que fazem parte da ética cavaleiresca, princípio básico que deve organizar a sociedade.

Se houvesse fidelidade entre os nobres não haveria necessidade dos reis. Em uma sociedade configurada a partir de vínculos pessoais, a fidelidade é imprescindível. O rei, na concepção do Conde, só é digno de fidelidade se souber respeitar os foros e costumes nobiliárquicos. Deve apoiar-se nos vínculos pessoais que sustentam a sociedade, a fim de manter a justiça e ordenar a mesma. A imagem do rei pacífico, capaz de promover a paz no reino é a personificação desse ideal.

O bom rei é ainda o rei cristão, temente a Deus. É o rei da Reconquista, que luta em defesa da cristandade, combate mouros, reconquista territórios e garante a unidade da cristandade.

Essa imagem "ideal" contrasta com uma realidade bem diferente, marcada por revoltas nobiliárquicas, disputas entre reis e infantes, como no caso português onde o Infante Afonso reivindicara o exercício da Justiça dentro do reino, fato que culminou na Guerra Civil (1319-1324). Reis que na busca da centralização não souberam relacionar-se com a nobreza, não levando em conta seus valores e tradições, não provendo a paz e nem garantindo o bem comum em seus reinos. 


\section{COMO CITAR ESTE ARTIGO}

\section{Referência electrónica:}

LIMA, Adriana Mocelim de Souza - "A construção de um modelo ideal de monarca no livro de linhagens do Conde Pedro de Barcelos". Medievalista [Em linha]. N9, (Dezembro de 2010). [Consultado dd.mm.aaaa]. Disponível em http://www2.fcsh.unl.pt/iem/medievalista/MEDIEVALISTA9lima9009.html. ISSN 1646-740X.

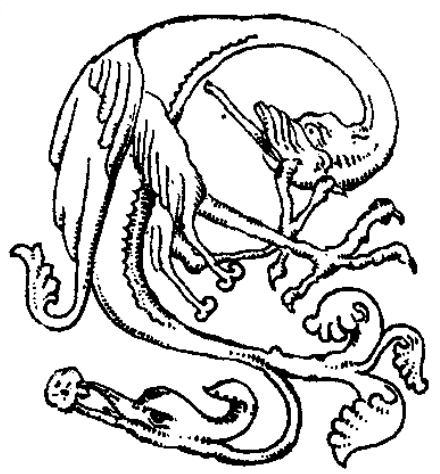

